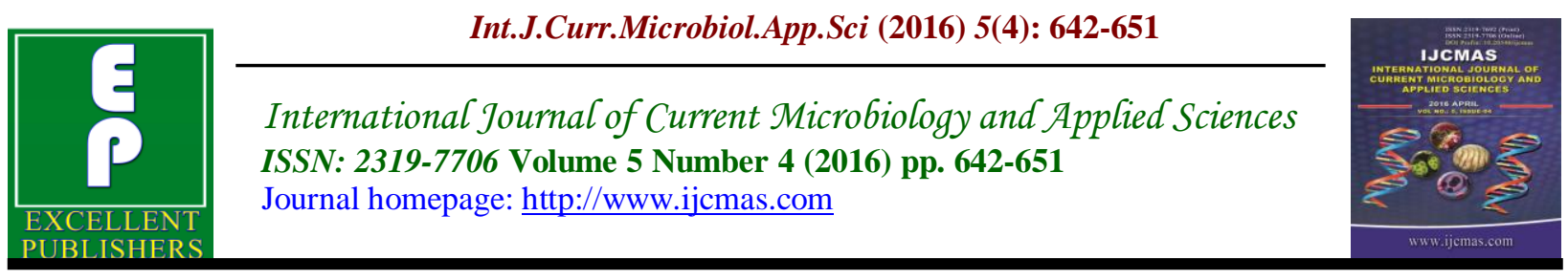

Original Research Article

http://dx.doi.org/10.20546/ijcmas.2016.504.073

\title{
Tolerance of Vicia faba to Elevated Concentrations of Copper Ions in Nutrient Medium
}

\author{
Khalid H. Alobaidi* \\ Department of Agricultural Biotechnology, College of Applied Biotechnology, \\ Al-Nahrain University, Iraq \\ *Corresponding author
}

\begin{abstract}
A B S T R A C T
Keywords

Vicia faba,

Tolerance to

Copper,

Indicator

plants,

Phytoremediation

\section{Article Info}

Accepted:

22 March 2016

Available Online:

10 April 2016

One of the most important legume crops in the Mediterranean Basin and Arab countries is Faba bean (Vicia faba), which is an efficient nitrogen fixer. This study conducted to evaluate plant Vicia faba in response to elevated concentration of copper in nutrient media and demonstrate that this plant potentially useful as phytoremediater for moderately contaminated areas with copper. In experiments on Vicia faba plant investigated in a hydroponic culture with different concentration of copper (control, 50, 100, 150, 200 and $250 \mu \mathrm{Mol} / \mathrm{L}$ ) experiments showed that the tested species refer to indicator plants. Established that the studied plants showed stability to the toxic effects of excessive levels of copper, determined by their ability to germinate and grow as well as accumulate free proline (19 times more than control at $250 \mu \mathrm{Mol} \mathrm{CuSO}_{4} / \mathrm{L}$ of media). Along with accumulation of a noticeable amount of metals in plant leaves (up to $60 \mu \mathrm{g}$ copper / g dry weight of plant tissue at $250 \mu \mathrm{Mol} \mathrm{CuSO} / / \mathrm{L}$ of media). These results characterize the studied plant species, Vicia faba, as potentially suitable as phytoremediater for moderately polluted areas with copper.
\end{abstract}

\section{Introduction}

Some heavy metals considered as essential micronutrients for animals, plants and many microorganisms, depending on the route and dose, as a results of metabolic interference and mutagenesis all heavy metals demonstrate toxic effects on living organism. Heavy metals can be a major problem for any biological organism as they may be reactive with a number of chemicals essential to biological processes (Kamran $e t$ al., 2013). Faba bean (Vicia faba) is one of the most important legume crops in the Mediterranean Basin. It is known to be an efficient nitrogen fixer of about $80 \%$ of nitrogen from the atmosphere (Huber et al., 1987); which, depends on availability of Rhizobium spp. that colonize the legume plants (Rodelas et al., 1999). It has an essential role concerning multipurpose of their usage as roasted in human diet, dried green or hay in animal feeding. Increasing in domestic consumption of dry beans due to consumer and scientific recognition of beans as a major health food. High protein level (18-41\% of Dry Matter) in dried seeds have been reported (Iyad W.Musallam et al., 
2004), than other cultivated plants so they are used as important source for human nutrition or serves as fodder by feeding livestock with fresh stems and leaves.

As in all cultivated plants, the main objective of the faba bean breeding programme are to overcome the specific problems of this plant and to get high yield and quality. On the other hand, since genotypic and environmental factors are components determining yield and quality in plants, a primary aim should be the determination of effect of genotypic factors in selection. As the effect of environment on yield and quality in plant.

Stability to the toxic effects of elevated copper levels of various plants, due to ability of their proline accumulation has been studied (Alobaidi et al., 2015). In order to clean the soil from heavy metal pollution, scientists developed a variety of technologies. One of most promising technique is phytoremediation-a method that based on the ability of the plants to clean up contaminated sites (Buravtsev, V.N. and Krylova, 2005; Krämer et al., 2005).

Phytoextraction method which is most commonly used for the purpose of detoxification that is based on the ability of certain species of plants absorbs heavy metal from the soil and accumulates them in the aerial organs (Barbafieri et al., 2011; Koshkin and Vagun, 2010; Chaney et al., 1997; Raskin et al., 1994). Phytoremediation offers a low cost and an environmentally friendly approach for decontaminating soils and waters of heavy metals.

\section{Materials and Methods}

\section{Conditions of Plant Cultivation and Carrying out Experiments}

Plants grown in different pattern depending on the experimental setup. Petri dishes to study the effect of $\mathrm{CuSO}_{4}$ on seeds germination, while 2 week germinated seedling transplanted into containers filled with aqueous nutrient solution (MS media) used for the estimation of the effect of elevated concentration of $\mathrm{CuSO}_{4}$

\section{Treatment of Seeds and Work with Seedlings}

Seeds obtained from Baghdad local markets, disinfected as follow, washed with tap water for 15 minutes then sterilized by $2 \% \mathrm{v} / \mathrm{v}$ sodium hypochlorite (Clorox) for 15 minutes and then washed extensively with sterilized distilled water. Petri dishes used with filter paper when working with seedlings, cultivation conducted in an incubator at $25 \mathrm{C}^{\circ} \cdot \mathrm{CuSO}_{4}$ solution used at a concentration of 10-300 $\mu \mathrm{M}$, with water used as control.

\section{Sowing and Cultivation the Initial Stage of Young Plants}

Disinfected seeds sown on the surface of moist perlite in plastic containers (40h30h8sm) with holes at the bottom, placing the container on a tray. To maintain the desired humidity the top of the container closed with glass plate and removing it only after sprouting.

\section{Replanting and Cultivation of Plants in Water Culture}

At the age of 14 days, the plants removed from the perlite by using spatula as possible without damaging the roots. Then the roots washed in a small volume of water to remove the perlite particles. The plants are then cultivated in 1-liter pot, three plants per pot. Aeration and mixing of the nutrient solution carried out by continuous and uniform supply of air. In water culture plants grown in a growth chamber at temperature 
around 25/20 $\mathrm{C}^{\circ}$ (day / night), 12-hour light photoperiod. For growing in water culture, using a MS medium (Murashig and Skoog, 1962) and $\mathrm{pH}$ adjusted to 5.8.

\section{Experimental Condition}

In the experiments used 5-6 week plants with 3-4 fully developed leaves. Exposure started by introduction of $\mathrm{CuSO}_{4}$ to the culture medium at concentrations of 10,25 , 50,100 and $150 \mu \mathrm{M}$. Changing the culture medium performed every 5 days. Duration was 7 days. As a control, plants grown on standard medium containing $0.25 \mu \mathrm{M}$ $\mathrm{CuSO}_{4}$.

Measurement of Seed Germination and Seedling Root Length

Assessing the impact of excess $\mathrm{Cu}$ germination seedling and root growth performed using at least three seeds in each petri dishes and each variant used three petri dishes. Disinfected seeds soaked in a solution of copper sulphate in concentrations of 10 - 300 microns. Seed germination carried out for 5 days, then determined the percentage of germinated seeds and measured seedlings root length. Root length of the Germinated seeds considered at least five $\mathrm{mm}$. Germination of each variant considered as a percentage - the number of germinated seeds relative to the total amount of seed.

\section{Measurement of Plant Biomass}

To evaluate the respond of the plants to the elevated concentration of $\mathrm{CuSO} 4$, biomass of plants materials measured at the $7^{\text {th }}$ day of exposure using sensitive electrical balance.

\section{Determination of Metal Ion Content in Plant Tissues}

Determination of the content of copper performed by wet ashing method (14). A weighed sample of previously dried plant material (typically $50 \mu \mathrm{g}$ ) placed in a test tube filled with a mixture of nitric acid (1.6 $\mathrm{mL})$ and hydrochloric acid $(0.5 \mathrm{ml})$ and left overnight. The next day, the sample tubes placed in a preheated to a temperature of $110^{\circ} \mathrm{C}$ thermostat, incubated for $1 \mathrm{hr}$ then a further $2 \mathrm{~h}$ at $180 \mathrm{C}^{\circ}$. To samples added one drop of concentrated hydrogen peroxide. The next day, decolorized. Transferred into measuring tube and adjusted with distilled water to a certain volume $(10-15 \mathrm{ml})$. Measuring the concentration of $\mathrm{Cu}$ was carried out on atomic absorption spectrophotometer «PG Instruments" (USA).

\section{Content of Free Proline}

The free proline was determined using the acid ninhydrin reagent method (15). To assess the content of proline in $1 \mathrm{ml}$ of the obtained plant extract added $1 \mathrm{ml}$ of glacial acetic acid and $1 \mathrm{ml}$ of ninhydrin reagent, incubated in a boiling water bath for 1 hour and then quickly cooled in ice. The color intensity was determined spectrophotometrically at $520 \mathrm{~nm}$ on a spectrophotometer «ThermoFisher Scientific, Genesys 20" (USA).

Proline content calculated using a calibration curve by the following formula:

$\mathrm{C}=\mathrm{E} * \mathrm{k} * \mathrm{~V} /(\mathrm{m} * 1000)$ where

C - Concentration of proline, M/g wet weight

E - Optical density

$\mathrm{k}$ - Coefficient calculated from the calibration curve, 217.49

V - Volume, to which brought extract, $\mathrm{ml}$

$\mathrm{m}$ - Mass of sample 


\section{Results and Discussion}

Effects of Elevated Concentrations of CuSO4 on Seed Germination and Seedling Growth

As described in the Materials and Methods section, disinfected three seeds of plant laid in a petri dish on filter paper, soaked with dissolved $\mathrm{CuSO}_{4}$ solutions at a concentration of $(50-300) \mu \mathrm{Mol}$, water served as the control. The number of germinated seeds counted and measured the length of the sprouts roots on $5^{\text {th }}$ day.

\section{Influence of $\mathrm{CuSO} 4$ on Root Growth During Germination of Seeds Vicia faba}

Elevated concentrations of cuper had a negative effect on seed root of Vicia faba, complete loss of germination occurred at (300) $\mathrm{MMol} \mathrm{CuSO}_{4}$ (death).Vicia faba greater stability clearly visible at $50 \mu \mathrm{Mol} \mathrm{CuSO}_{4}$ (table 1).

Further evaluation of the effect of copper on the growth of the seedlings roots. Elevated concentrations of $\mathrm{CuSO}_{4}$ significantly reduces the length of seedling roots of Vicia faba (Table 1). Significant decrease in growth began with $100 \mu \mathrm{Mol} \mathrm{CuSO}$ and at the highest concentration $\left(250 \mu \mathrm{Mol} \mathrm{CuSO}_{4}\right)$ used, root growth decreased to $65 \%$ of control. These results suggest that in the initial stages of plant Vicia faba showed fairly good resistance to high concentrations of $\mathrm{CuSO}_{4}$.

\section{Effects of $\quad$ Elevated $\quad \mathrm{CuSO4}$ Concentrations on Plants Growth in Aqueous Culture}

After 14-day-old seedlings of Vicia faba, chosen to study, germinated in pearlite, were transplanted into vessels with medium Murashige-Skoog (MS), where they grew within 3-4 weeks. Then replaced with standard medium vessels on the same medium but supplemented with different concentrations of $\mathrm{CuSO}_{4}(50$ to and 250 $\mu \mathrm{Mol})$. After 10 days of stress exposure, the plants removed from the vessel and weighed to calculate the cumulative raw biomass, and then carried out the study of copper accumulation in leaf tissue and the accumulation of proline. Effect of $\mathrm{CuSO}_{4}$ on biomass can show in (Table 2).

\section{Accumulation of Biomass}

Results presented in Table 2, which shows that growth of Vicia faba decrease when concentration of $\mathrm{CuSO}_{4}$ increase. So at 150 $\mu \mathrm{Mol} \mathrm{CuSO}_{4}$ reduced raw biomass weight by $44 \%$, while $200 \mu \mathrm{MolCuSO}_{4}$ reduced raw biomass weight by $57 \%$, and at $250 \mu \mathrm{Mol}$ $\mathrm{CuSO}_{4}$ reduced raw biomass weight by $66 \%$ (Fig. 1).

\section{Effect of Copper on the Content of Free Proline}

The possible reasons for the differences in resistance to excessive concentrations of copper in Vicia faba also carried out, to study the influence of stress factors on the content of proline due to its known function as a chemical chaperone and an antioxidant. Elevated levels of $\mathrm{CuSO}_{4}$ in the culture medium caused a significant accumulation of proline in the leaves of plants studied Vicia faba. Even at the concentration of 50 $\mu \mathrm{Mol} \mathrm{Cu}$, concentration of proline in leaves was increased to 8 times more than the control in relation to the values of the plants control (Fig 2). The maximum accumulation of proline at $250 \mu \mathrm{Mol} \mathrm{CuSO} \mathrm{Cup}_{4}$ to 14 . $\mu \mathrm{Mol} / \mathrm{g}$ (Table 3).

\section{Accumulation of Copper in Plant Tissues}

The accumulation of heavy metals in aboveground plant organs is one of the most important parameters that determine the 
phytoremediation ability of plants. Therefore, in this study it was necessary to assess the ability of the studied cultures to accumulation of copper in the plant leaves.Adding excess $\mathrm{CuSO}_{4}$ in nutrient solution resulted in a significant accumulation of copper in the plants organs (Table 4). Greater accumulation shown at higher concentration, which reaches to about 5 times more than in the control (Fig. 3).

From this result, suggest that Vicia faba have moderate phytoremediation potential and ability to tolerate high concentration of $\mathrm{CuSO}_{4}$
Pollution with Heavy Metals considered as a serious environmental problem of our time, which adversely affects both the agricultural and plant communities, as well as on human health. At present, more and more scientific and practical interest were focused on the problem of plant adaptation to damaging abiotic factors with natural and anthropogenic origin, among them special attention attracts toxic effects of heavy metals (HM). The use HM-resistant plants to clean the environment from anthropogenic pollution is advisable, that can extract and accumulate metals in the aboveground organs (phytoremediation).

Table.1 Growth of Roots of Seedlings Vicia faba Depending on the Concentration of CuSO4

\begin{tabular}{|c|c|c|}
\hline Variant & roots length $\mathbf{~ m m}$ & \% \\
\hline control & 14.3 & 100 \\
\hline 50 & 11.5 & 81 \\
\hline 100 & 9.5 & 67 \\
\hline 150 & 7.5 & 53 \\
\hline 200 & 6.9 & 48 \\
\hline 250 & 5.0 & 35 \\
\hline
\end{tabular}

Table.2 Effect of CuSO4 on Biomass of Vicia faba

\begin{tabular}{|c|c|}
\hline Variant & Raw biomass (plant/g) \\
\hline control & 7.60 \\
\hline 50 & 7.34 \\
\hline 100 & 5.90 \\
\hline 150 & 4.25 \\
\hline 200 & 3.24 \\
\hline 250 & 2.60 \\
\hline
\end{tabular}

Table.3 Proline Content in Leaves of Vicia faba $\mu \mathrm{Mol} / \mathrm{g}$ Biomass

\begin{tabular}{|c|c|}
\hline Variants & Leaves \\
\hline control & 0.75 \\
\hline 50 & 6.25 \\
\hline 100 & 8.21 \\
\hline 150 & 10.22 \\
\hline 200 & 12.4 \\
\hline 250 & 14.6 \\
\hline
\end{tabular}


Table 4.Accumulation of CuSo4 in leaves $\mu \mathrm{g} / \mathrm{g}$ dry weight

\begin{tabular}{|c|c|}
\hline Variant & leaves \\
\hline control & 11.5 \\
\hline 50 & 39.5 \\
\hline 100 & 44.3 \\
\hline 150 & 54.2 \\
\hline 200 & 56.3 \\
\hline 250 & 59.6 \\
\hline
\end{tabular}

Fig.1 Percentage of Plants Biomass Accumulation in Different CuSO4 Concentration

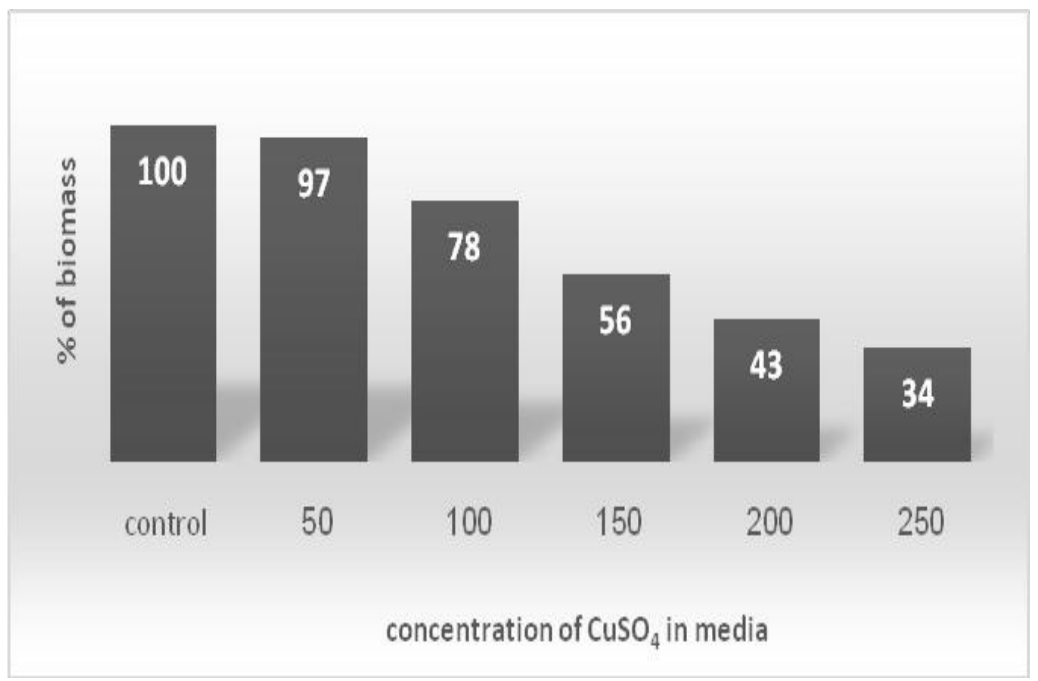

Fig.2 Proline Content in Plant Leaves at Different Concentration of CuSO4, Control taken as a Unit

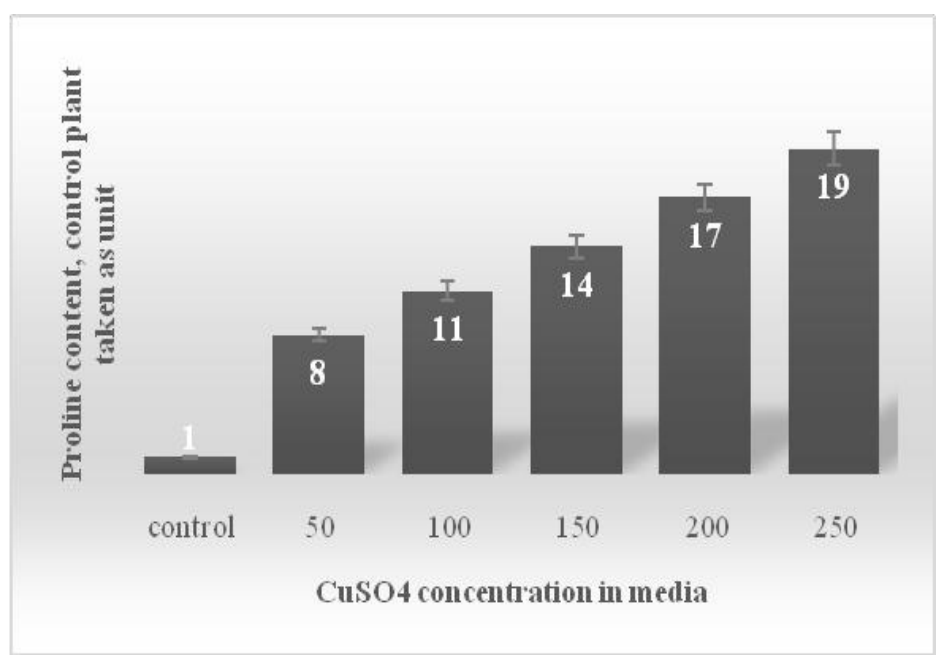


Fig.3 Copper Accumulation in Plants Leaves at Different Concentration of $\mathrm{CuSO}_{4}$, Control taken as a Unit

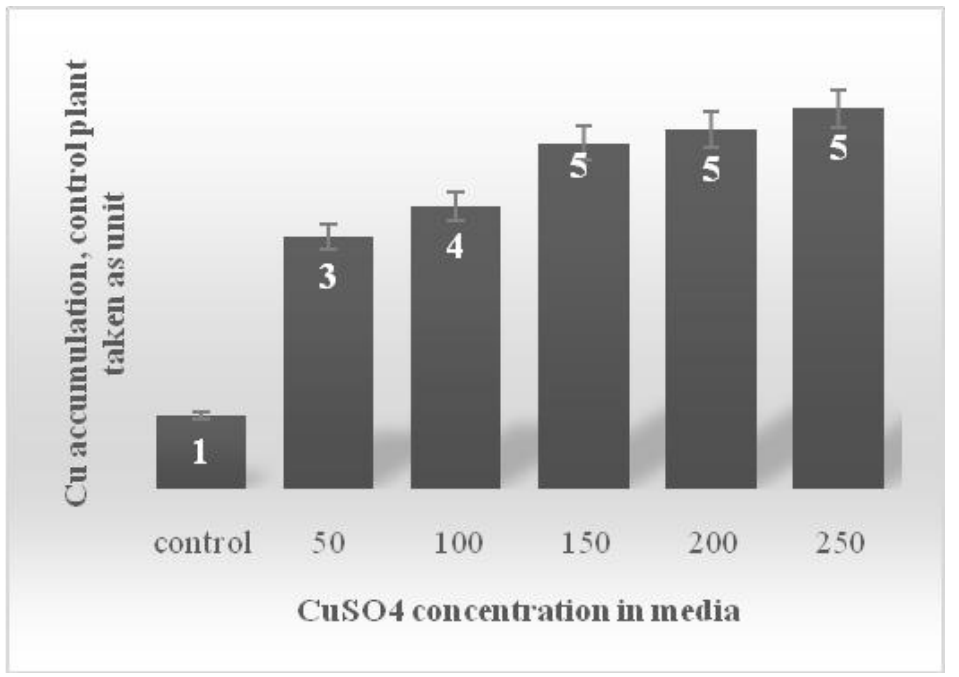

For phytoremediation of contaminated areas using HM, plants have the ability to rapidly absorb metals from the soil, which is associated with the ability of the metal ion transported throughout the plant. One of the species that are promising for phytoremediation is Vicia faba, sufficiently high resistance to (HM), has a welldeveloped aboveground mass (Ben Ghnaya et al., 2009; Ebbs and Kochian, 1997), allowing the accumulation of significant amounts of soil HM.

Copper is trace essential elements involved in a variety of physiological and biochemical processes in living organisms. For example, copperhas important role in response for the operation of a number of enzymes and non-enzymatic proteins nature. An indispensable element of this is because when plants growing in water culture copper is an essential component of nutrient mixtures. In particular, the medium used in the experiments with Vicia faba, contained 0.025 milligrams/liter $\mathrm{CuSO}_{4}$.

In this work analysis of the effect of copper on plants of Vicia fababeen done. To characterize the plant we have studied the action of elevated concentrations of $\mathrm{CuSO}_{4}$ on seed germination and seedling growth on young plants growing in water culture. Indicators such as growth and accumulation of plant biomass, accumulation of copper in the tissues of plants, and the content of free proline, examined in response to stress exposure to high concentrations of $\mathrm{CuSO}_{4}$.

At the level of seed germination and the initial growth stage of the plant Vicia faba seedlings showed resistance to higher copper concentrations in excess, since inhibition of germination occurred at copper concentrations in excess of $300 \mu \mathrm{Mol}$.As mentioned, already at a small increase in the copper concentration in the medium was observed and the inhibition of growth of several physiological parameters.

Clear signs of the negative effect of copper is inhibition of the development of the root system (tab.1).It is known that the plants have developed efficient mechanisms for not only the absorption of any nutrient deficiency from the soil, but also the mechanisms of absorption of mineral limit elements at their highest concentrations in the environment (Kabata - Pendias and Pendias, 2001). 
Accumulation of copper in plant tissues depended on the concentration of $\mathrm{CuSO}_{4}$ in the medium, time of exposure and the type of plant. With increasing concentration of copper in the medium accumulated amount of metal in plants increased, increasing with longer exposure. Thus, the accumulation in the tissues was higher in Vicia faba (Table. 4).

As can be seen from the data, Vicia faba were very effective in Heavy Metal phytoextraction from the culture medium, which was manifested in their ability to actively accumulate $\mathrm{Cu}$ in the aboveground organs. Therefore, we can conclude that Vicia faba can be used for purposes of phytoremediation.

Many researchers (Schutzendubel and Polle, 2002; Blokhina et al., 2003; Mediouni et al., 2009) Furthermore, when exposed to stressors plants observed rapid inactivation constitutive pool of antioxidant enzymes.

At the present time can be considered universally accepted idea that the low molecular weight organic antioxidants in some cases are able to more effectively protect the metabolism from the damaging effect of ROS (radical oxygen species). These substances belong to some compatible osmolytes, one of which is the amino acid proline. Proline is a versatile organic tread compound. It acts as an osmolyte and antioxidant energy substrate, a source of reducing equivalents, nitrogen, and carbon, as well as a regulator of expression of stress response genes. In addition, proline exhibits chemical chaperone function, protecting the native conformation of macromolecules and membranes under stress (Kuznetsov et al., 2011). It is known that the proline content is increased in the presence of heavy metals ions (Cheng, 2003).
As in the works of other researchers (Maree et al., 2012) in this study, it was shown that (Table. 3) proline content increased by the action of $\mathrm{CuSO}_{4}$. It is interesting that at low concentrations of $\mathrm{CuSO}_{4}$ proline accumulated in the leaves of plant. Proline is a complex response of plants to the impact of stress factors, and it is important to improve plant resistance to adverse environmental conditions (Hong et al., 2000; Mattioli et al., 2008; Székely et al., 2008). According to some authors (Kuznetsov and Shevyakova, 1997), proline is one of the most important components of the system to protect cells from the effects of stress factors. There is no doubt that the strong increase in proline content in Viciafabais in response to high concentrations of HM. The high level of copper accumulation in the tissues and at the same time, the high resistance of plants can occur only through the operation of a complete system of intracellular detoxification mechanisms of copper in plant organs Vicia faba.

\section{References}

Alobaidi, K.H., Bashmakova, E.B., Kholodova, V.P. 2015. "Response of Two Brassica Species to the Toxic Effect of Different Copper Concentration". J. Environ. Protection, 6: 719-725.

Barbafieri, M., Dadea, C., Tassi, E., Bretzel, F., Fanfani, L. 2011. "Uptake of Heavy Metals by Native SpeciesGrowing in a Mining Area in Sardinia". Int. J. Phytoremediation, 13: 985-997.

Bates, L.S., Waldren, R.P., Teare, I.D. 1973. "Rapid Determination of Free Proline for Water-Stress Studies". Plant and Soil, 39: 205-207.

Ben Ghnaya, A., Charles, G., Hourmant, A., Ben Hamida, J., Branchard, M. 2009. 
"Physiological Behaviour of Four Rapeseed Cultivar (Brassica napus L.) Submitted to Metal Stress" $C$. $R$. Biol., 332: 363-370.

Blokhina, O., Virolainen, E., Fagerstedt, K.V. 2003. "Antioxidants, oxidative damage and oxygen deprivative stress: a review" Annals of Bot., 91: 179-194.

Buravtsev, V.N., Krylova, N.P. 2005. "Modern Technological Schemes of Phytoremediation of Polluted Soils". Agri. Biol., 5: 67-73 (in Russian).

Chaney, R.L., Malik, M., Li, Y.M., Brown, S.L., Brewer, E.P., Angle, J.S., Baker, A.J.M. 1997. "Phytoremediationof Soil Metals". Curr. Opinion in Biotechnol., $\quad$ 8: 279-284. http://dx.doi.org/10.1016/S09581669(97)80004-3

Cheng, S. 2003. "Effects of Heavy Metals on Plants and Resistance Mechanisms". Environ. Sci. Poll. Res., 10: 256-264.

Ebbs, S.D., Kochian, L.V. 1997. "Toxicity of zinc and copper to Brassica species: Implications for phytoremediation". J. Environ. Qual., 26: 776-781.

Hong, Z., Lakkineni, K., Zhang, Zh., Verma, D., Pal, S. 2000. "Removal of feedback inhibition of delta(1)pyrroline-5-carboxylate synthetase results in increased prolineaccumulation and protection of plants from osmotic stress" Plant Physiol., 122: 1129-1136.

Huber, R., Keller, E.R., Schwendimann, F. 1987. "Effect of biological nitrogen fixation by faba beans (Vicia faba L.) on the nitrogen economy of the soil," Fabis news1, Vol. 17, pp. 14-20.

Ivanova, E.M., Kholodov, V.P., Kuznetsov. 2010. "Biological effects of high concentrations of copper and zincsalts, and the nature of their interaction in rapeseed plants". Plant Physiol., 7: 864-873.

Iyad, W., Musallam, Ghazi, N., Al-Karaki, Khalil, I., Ereifej, Abdel-Rahman, M., Tawaha. 2004. "Chemical Composition of Faba Bean Genotypes under Rainfed and Irrigation Conditions" Int. J. Agri. Biol., Vol. 6, No. 2.

Kabata - Pendias, A., Pendias, H. 2001. "Trace Elements in Soils and Plants", $3^{\text {rd }}$ Edition, CRC Press, Boca Raton, London, p. 413.

Kamran, S., Shafaqat, A., Samra, H., Sana, A., Samar, F., Muhammad, B.S., Saima, A.B., Hafiz, M.T. 2013. "Heavy Metals Contamination and what are the Impacts on Living Organisms," Greener J. Environ. Management and Pub. Safety, Vol. 2(4) pp. 172-179.

Koshkin, E., Vagun, I. 2010. "Phytoremediation Capability of Brassica napus Grown on Soils, Contaminated withHeavy Metals". FESPB-XVII Congress of the Federation of European Societies of Plant Biology, Book of Abstracts, Valencia, 54.

Krämer, U. 2005. "Phytoremediation: Novel Approaches to Cleaning up Polluted Soils". Curr. Opinion in Biotechnol., 16: 133-141. http://dx.doi.org/10.1016/j.copbio.200 5.02 .006

Kuznetsov, Shevyakova, N.I. 1997. "Stress responses of tobacco cells to high temperature and salinity. Proline accumulation and phosphorylation of polypeptides". Physiol. Plant, 100: 1035-1040.

Kuznetsov, V.V., Dmitrieva, G.A. 2011. "Plant Physiology". Higher School Publishing, Moscow, 744-748.

Maree, M.M., Raldugina, G.N., Alobaidi, K.H. 2012. "Comparative analysis of 
stabilty of 2 varieties of springrape (Brassica napus L.) to the effect of the ions copper and zinc" Bulletin of RPFU, 2: 16-24.

Mattioli, R., Marchese, D., D'Angeli, S., Altamura, M.M., Costantino, P., Trovato, M. 2008. "Modulation of intracellular proline levelsaffects flowering time and inflorescence architecture in Arabidopsis". Plant Mol. Biol., 66: 277-288.

Mediouni, C., Ben Ammar, W., Guy, H., Chaboute, M.E. 2009. "Cadmium and copper induction of oxidative stress and Antioxidative response in tomato (Solanum licopersicum L.) leaves", Plant Growth Regulation, 57: 89-99.

Murashige, T., Skoog, F. 1962. "A revised medium for rapid growth and bioassays with tobacco tissue cultures". Physiologia Plantarum, 15: 473-497.

Raskin, I., Kumar, P.B., Dushenkov, V., Salt, D.E. 1994. "Bioconcentration of Heavy Metals by Plants". Curr. Opinion in Biotechnol., 5: 285-290. http://dx.doi.org/10.1016/09581669(94)90030-2

Rodelas, B., GonzaÂlez-LoÂpez, J., Pozo, C., Salmerô̂n, V., MartõÂnezToledo, M.V. 1999. "Response of Faba bean (Vicia faba L.) to combined inoculation with Azotobacter and Rhizobium leguminosarum bv. viceae," Appl. Soil Ecol., Vol. 12, pp. 51-59.

Schutzendubel, A., Polle, A. 2002. "Plant responses to abiotic stresses: Heavy metal-induced oxidative stress and protection by mycorrhization". $J$. Experimental Bot., 53: 1351-1365.

Székely, G., Abrahám, E., Cséplo, A., Rigó, G., Zsigmond, L., Csiszár, J., Teklić, T., Hancock, J.T., Engler, M., Paradicović, N., Cesar, V., Lepeduš, H., Štolfa, I., Bešlo, D. 2008. "Antioxidative responses in radish (Raphanus sativus L.) plants stressed by copper and lead in nutrient solution and soil". Acta Biol Crac., 50(2): 7986.

\section{How to cite this article:}

Khalid H. Alobaidi. 2016. Tolerance of Vicia faba to Elevated Concentrations of Copper Ions in Nutrient Medium. Int.J.Curr.Microbiol.App.Sci.5(4): 642-651. doi: http://dx.doi.org/10.20546/ijcmas.2016.504.073 